\title{
STUDIES OF STREPTOCOCCAL FIBRINOLYSIS. III. A QUANTI- TATIVE METHOD FOR THE ESTIMATION OF SERUM ANTIFIBRINOLYSIN ${ }^{1}$
}

\author{
By MELVIN H. KAPLAN in COLLABoration with THE COMMISSION ON ACUTE \\ RESPIRATORY DISEASES 2
}

\author{
(From the Respiratory Diseases Commission Laboratory, Regional Station Hospital, Section 2, \\ Fort Bragg, North Carolina)
}

(Received for publication September 5, 1945)

The plasma clots of patients convalescent from hemolytic streptococcal infections have frequently been found resistant to dissolution by fibrinolysin $(1,2)$. The resistance of such clots is generally regarded as a specific response to streptococcal infection ; consequently, tests for clot resistance have been widely employed as a diagnosic aid in the study of streptococcal disease. In general, the results of such antifibrinolysin tests have indicated that the development of antifibrinolytic properties in the plasma is correlated with infection due to the $\beta$-hemolytic streptococcus $(3,4)$. In some instances, however, the results have appeared to be non-specific $(5,6)$.

As a result of recent studies of streptococcal fibrinolysis and its inhibition ( 7 to 9 ) it has been possible to understand more fully the qualitative and quantitative factors which participate in the antifibrinolytic reaction. It was found that the resistance of plasma clots could be attributed to each of the following three factors: (a) the presence in the plasma of specific antibody, antifibri-

\footnotetext{
1 This investigation was supported through the Commission on Acute Respiratory Diseases, Board for the Investigation and Control of Influenza and Other Epidemic Diseases in the Army, Preventive Medicine Service, Office of The Surgeon General, United States Army, and by grants from the Commonwealth Fund, the W. K. Kellogg Foundation, the John and Mary R. Markle Foundation and the International Health Division of the Rockefeller Foundation to the Board for the Investigation and Control of Influenza and Other Epidemic Diseases for the Commission on Acute Respiratory Diseases.

2 Members and professional associates of the Commission on Acute Respiratory Diseases are John H. Dingle, Major, M.C., A.U.S. Director; Theodore J. Abernethy, Major, M.C., A.U.S.; George F. Badger, Major, MC., A.U.S.; Norman L. Cressy, Major, M.C., A.U.S.; A. E. Feller, M.D; Irving Gordon, MD.; Alexander D. Langmuir, Major, M.C., A.U.S.; Charles H. Rammelkamp, M.D.; Elias Strauss, Captain, M.C., A.U.S., and Hugh Tatlock, Captain, M.C., A.U.S.
}

nolysin; (b) the presence of antiprotease; and (c) the deficiency in the plasma of a lytic factor (10). Thus, a positive antifibrinolysin test is not necessarily a specific indication of the presence of antifibrinolysin. Further, quantitative studies (11) of the variables in the antifibrinolysin test have suggested that lysis time is not an adequate measure of antifibrinolysin content. It was pointed out that the antifibrinolysin content of a plasma clot lysed in 24 hours is only slightly greater than that of a clot lysed in 1 hour. In some studies (12), the antifibrinolysin content of plasma clots has been measured by the amount of fibrinolysin required to permit dissolution. However, this procedure appears objectionable in principle, because of the evidence that fibrinolysin and antifibrinolysin do not combine stoichiometrically, but in multiple proportions (9). It was also observed that fibrinolysin and antifibrinolysin do not combine instantaneously: Approximately 30 minutes were required for completion of the reaction (9).

By suitable control of the variables in the fibrinolytic and antifibrinolytic reactions, a more reliable method for the quantitative estimation of antifibrinolysin was devised. In this method, the estimation of antifibrinolysin was based on the determination of the highest dilution of serum which neutralized an arbitrary unit of fibrinolysin. It was found that the serological method employed minimized the non-specific effects due to the presence of antiprotease and the deficiency of lytic factor. This method of antifibrinolysin titration and the results of its application are described in the present report.

\section{MATERIALS AND METHODS}

1. Fibrinogen. Lyophilized Fraction $I^{3}$ (13) of the plasma proteins was used as the source of fibrinogen.

3 The preparation employed was Fraction I of the plasma proteins prepared by the Department of Physical Chem- 
Two fibrinogen solutions were employed: (1) Fibrinogen Solution A, for standardization of fibrinolysin, contained $100 \mathrm{mgm}$. of powdered Fraction I in $33.4 \mathrm{ml}$. of buffered saline; and (2) Fibrinogen Solution B, for use in the routine serum titrations, consisted of $600 \mathrm{mgm}$. of Fraction I dissolved in $100 \mathrm{ml}$. of buffer. Solution B was exactly twice the concentration of Solution A.

Complete dissolution was readily obtained by warming the mixtures in a water bath at $37^{\circ} \mathrm{C}$. for at least 30 minutes with periodic shaking. The standard fibrin clot formed from each of these solutions finally contained 0.14 per cent Fraction I ( 0.04 per cent fibrinogen) in a volume of $2.2 \mathrm{ml}$.

2. Buffered saline. This was a solution of $0.01 \mathrm{M}$ phosphate in $\mathbf{0 . 8 5}$ per cent sodium chloride at $\mathrm{pH} 7.4$ Solutions of all the reagents employed, as well as all dilutions of serum, were made in this buffer.

3. Thrombin. A highly active commercial rabbit thrombin preparation was employed in a 1 to 10 dilution.

4. Fibrinolysin. The source of fibrinolysin was a group A, non-typable strain of $\beta$-hemolytic streptococcus (no. 98) isolated from the blood of a patient with erysipelas. Fibrinolysin was obtained as an alcoholic precipitate from a culture filtrate according to the method of Garner and Tillett (14). The precipitate was dissolved in a volume of buffer one-half that of the original culture filtrate; and the resulting solution was dispensed accurately in $5.0 \mathrm{ml}$. lots into small ampules. These were dried by the lyophile process or stored in a $\mathrm{CO}_{2}$ refrigerator at $-70^{\circ} \mathrm{C}$. Each ampule of dried fibrinolysin preparation was reconstituted with $5.0 \mathrm{ml}$. of distilled water just prior to use.

5. Stability of reagents. Studies of the factors influencing the antifibrinolysin test have demonstrated that fibrinolysin deteriorates markedly when kept at $37^{\circ} \mathrm{C}$. for 24 hours $(14,15)$. In addition, the susceptibility of fibrin clots to lysis may vary with the age of the thrombin and fibrinogen preparations used (16). It was necessary therefore to test the stabilities of the reagents employed under the conditions required by the present method. These studies yielded the following results:

(a) Fibrinolysin preparations exposed for 4 hours to a temperature of $37^{\circ} \mathrm{C}$. showed no measurable loss of activity.

(b) Fibrinogen preparations allowed to stand at $25^{\circ} \mathrm{C}$. for 4 hours were no different in their susceptibility to lysis than fresh solutions.

(c) Thrombin solutions possessed adequate activity after storage at $4^{\circ} \mathrm{C}$. for periods exceeding 2 months. Furthermore, neither lytic factor nor antiprotease was found to be associated with this product.

Thus, for the purpose of the method described, the stabilities of the above reagents were entirely adequate.

istry, Harvard Medical School, Boston, Mass., from blood collected by the American Red Cross, under a contract, recommended by the Committee on Medical Research, between the Office of Scientific Research and Development and Harvard University.

4 "Hemostatic Globulin," Lederle Laboratories. Inc.
Newly prepared solutions were employed each day the test was performed.

\section{GENERAL PROCEDURE}

The estimation of serum antifibrinolysin was based on the determination of the highest dilution of serum which neutralized the lytic activity of a given arbitrary unit of fibrinolysin. Residual fibrinolysin activity was indicated by lysis of a fibrin clot. The accuracy of the method then depended essentially upon the standardization of the fibrinolysin employed, and upon the sensitivity of the fibrinolytic indicator system.

\section{Standardization of fibrinolysin}

Fibrinolysin concentration was measured under controlled conditions by the lysis time of a standard fibrin clot. It was found that significant variations of fibrinolysin concentration could be measured most accurately at lysis times near 30 minutes. More rapid lysis times did not represent a range of sufficient sensitivity to changes in fibrinolysin; while, with lysis times more prolonged, a range of excessive sensitivity was reached which made practical measurements difficult.

The unit of fibrinolysin adopted was $0.5 \mathrm{ml}$. of the highest dilution which completely lysed a standard fibrin clot in 30 minutes. This concentration of fibrinolysin was determined by testing progressive dilutions of the stock preparation. The accuracy of the titration was found to be dependent upon the following conditions :

(a) It was necessary that the fibrin clot be reproducible in content of fibrinogen and lytic factor; and furthermore, that the content of lytic factor be sufficient to permit a high degree of susceptibility to fibrinolysis.

(b) Since the actual lytic agent in streptococcal fibrinolysis is the serum protease, it was essential that the tests be carried out under physicochemical conditions optimal for the activity of the protease. Optimal activity for this enzyme has been reported at $\mathrm{pH} 7.2$ to 7.4 and at a temperature of 37 to $40^{\circ} \mathrm{C}$. (17).

In accordance with these observations, all fibrinolytic titrations were run with a single lot of Fraction I, which thus permitted simultaneous control of both fibrinogen and lytic factor concentrations. The $\mathrm{pH}$ of the test mixtures was 7.2, while the fibrinolytic tests were carried out at $37^{\circ} \mathrm{C}$.

\section{Procedure for standardization of fibrinolysin}

The method of standardization consisted of a preliminary and a final titration. For the preliminary titration, $5.0 \mathrm{ml}$. of the stock fibrinolysin preparation were diluted to 75.0 ml. to give a $1 / 15$ dilution. Six tubes were set up containing $1.0 \mathrm{ml}$. of the following dilutions of fibrinolysin: $1 / 30,1 / 40,1 / 50,1 / 60,1 / 75$, and $1 / 100$. To form the standard clots, $1.0 \mathrm{ml}$. of Fibrinogen Solution A, and 0.2 $\mathrm{ml}$. of thrombin were added. Clotting occurred in $2 \mathrm{~min}$ utes. Incubation was carried out for 30 minutes at $37^{\circ} \mathrm{C}$. The highest fibrinolysin dilution which effected complete dissolution of the clot was taken as the preliminary titer. A clot was regarded as completely lysed if no fibrin shreds or strands were visible upon shaking the tube. 
For the final titration, either a $1 / 30$ or a $1 / 60$ dilution of fibrinolysin was employed, depending on the preliminary titer. The fibrinolysin solution was added to 5 tubes in decrements of $0.05 \mathrm{ml}$. within the range of dilutions indicated by the preliminary titer. The volume of each tube was made up to $1.0 \mathrm{ml}$. with buffered saline. One $\mathrm{ml}$. of Fibrinogen Solution A and $0.2 \mathrm{ml}$. of thrombin were added; and after clotting, the tubes were incubated for 30 minutes. The highest dilution permitting complete dissolution of the standard fibrin clot was determined. Since only $0.5 \mathrm{ml}$. amounts of fibrinolysin were employed in the test, exactly twice this concentration was used in the standard solution of fibrinolysin.

\section{Titration of serum}

Previous studies (9) have indicated that the union of fibrinolysin and antifibrinolysin is 95 to 98 per cent complete after incubation for 30 minutes at $37^{\circ} \mathrm{C}$. The estimation of the serum antifibrinolysin titer was then based upon the determination of the highest dilution of serum which, after incubation for 30 minutes, completely neutralized 1 unit of fibrinolysin. The procedure for the titration of serum antifibrinolysin was as follows:

To a series of tubes containing $1.0 \mathrm{ml}$. of successive dilutions of serum, were added $0.5 \mathrm{ml}$. amounts ( 1 unit) of standard fibrinolysin solution. After incubation for 30 minutes at $37^{\circ} \mathrm{C}$., $0.5 \mathrm{ml}$. of Fibrinogen Solution B and $0.2 \mathrm{ml}$. of thrombin were added to each tube to form the standard clot. The tubes were incubated at $37^{\circ} \mathrm{C}$. for 60 minutes, and then examined for the presence of lysis. The reciprocal of the highest dilution of serum which completely prevented lysis of the clot was taken as the titer of the serum. A clot was regarded as lysed if it "ran" or "slid" in the slightest degree when the tube was inverted for 10 seconds and tapped gently 2 or 3 times.

The range of serum dilutions employed extended from $1 / 50$ to $1 / 2000$ (initial dilutions). For each serum both a preliminary and final titration were run. The preliminary test included 3 serum dilutions: $1 / 200,1 / 400$, and $1 / 600$; while the final titration employed 4 dilutions within the range indicated by the preliminary titer. For the final titration, it was found convenient to divide the sera into 5 groups :

Group $1: 1 / 50,1 / 100,1 / 150,1 / 200$

Group 2: $1 / 150,1 / 200,1 / 300,1 / 400$

Group 3: 1/300,1/400,1/500,1/600

Group $4: 1 / 500,1 / 600,1 / 800,1 / 1000$

Group 5 : 1/800, 1/1000, 1/1400, 1/1800

These progressive dilutions were not based on a logarithmic scale, since it was desired to increase the sensitivity of the method at the higher serum dilutions.

It is to be noted that an incubation period of 60 minutes was required to indicate the presence of residual fibrinolysin activity. The selection of this 60 -minute incubation period was based on the observation (9) that a lysis time of 1 hour represents approximately the minimal concentration of fibrinolysin which is capable of producing complete lysis. Consequently, if lysis to any degree did not occur within 60 minutes. it was concluded that neutrali- zation of fibrinolysin was complete. It is also to be pointed out that the concentration of the standard unit of fibrinolysin was 1.5 times that effecting lysis of the clot in 60 minutes (9). This concentration of the standard solution of fibrinolysin was found to reduce the effect of slight indeterminate errors, and thus increased the reproducibility of the method.

\section{Reproducibility}

To establish the reproducibility of the method, the antifibrinolysin titers of a set of 5 sera were determined each day the test was performed. Each group of serum titrations was made with a newly standardized fibrinolysin solution. Approximately 20 successive titrations were run for each serum. It was thus possible to test not only the reproducibility of the absolute titers of the sera from day to day, but also to observe the constancy of the relationship of the serum titers to each other.

The results of the repeated antifibrinolysin determinations are given in Table I. It may be observed that the

TABLE I

Results of the daily titration of antifibrinolysin in 5 sera

\begin{tabular}{l|c|c|c|c|c}
\hline \hline Date & $\begin{array}{c}\text { Serum } \\
203-\mathrm{B}\end{array}$ & $\begin{array}{c}\text { Serum } \\
216-\mathrm{D}\end{array}$ & $\begin{array}{c}\text { Serum } \\
216-\mathrm{B}\end{array}$ & $\begin{array}{c}\text { Serum } \\
229-\mathrm{C}\end{array}$ & $\begin{array}{c}\text { Serum } \\
215-\mathrm{A}\end{array}$ \\
\cline { 1 - 3 } $7 / 12$ & 150 & 200 & 300 & 600 & \\
$7 / 15$ & 150 & 200 & 300 & 600 & \\
$7 / 19$ & 150 & 300 & 300 & 500 & 400 \\
$7 / 20$ & 150 & 300 & 400 & 500 & 400 \\
$7 / 22$ & 150 & 300 & 300 & 600 & 500 \\
$7 / 25$ & 150 & 200 & 200 & 500 & 400 \\
$7 / 26$ & 150 & 300 & 400 & 600 & 500 \\
$7 / 27$ & 150 & 300 & 400 & 600 & 500 \\
$7 / 28$ & 150 & 300 & 300 & 600 & 500 \\
$8 / 1$ & 100 & 200 & 200 & 500 & 500 \\
$8 / 1$ & 100 & 150 & 150 & 600 & 400 \\
$8 / 2$ & 200 & 400 & 300 & 800 & 600 \\
& & & & & \\
$8 / 4$ & 150 & 400 & 200 & 600 & 400 \\
$8 / 5$ & 200 & 400 & 200 & 800 & 500 \\
$8 / 8$ & 100 & 200 & 150 & 600 & 300 \\
$8 / 9$ & 100 & 200 & 150 & 500 & 300 \\
$8 / 10$ & 150 & 300 & 150 & 1000 & 400 \\
$8 / 15$ & 100 & 150 & 150 & 800 & 300 \\
$8 / 16$ & 150 & 200 & 150 & 800 & 400 \\
$8 / 18$ & 100 & 300 & 200 & 800 & 400 \\
\hline & & & & & \\
\hline
\end{tabular}

absolute titer of a given serum varied to some extent when repeated on different days. However, the relationship of the titers of the 5 sera to each other in any given run was relatively constant.

On analysis of these repeated titrations, it was concluded that a difference in titer of any two successive tube dilutions between two sera titrated in the same run was probably significant. In the routine performance of the test, therefore, acute-phase and convalescent sera were run with the same standard fibrinolysin. A difference of at least two dilution increments was regarded as indicating a significant change in antifibrinolysin content. 
Subsequent studies correlating the antifibrinolysin response with the production of antistreptolysin " $O$ " (18) antibodies have amply confirmed this conclusion.

\section{DISCUSSION}

The serological antifibrinolysin test described in the present paper possesses a number of advantages over the plasma test. Firstly, non-specific antifibrinolytic effects due to the presence of antiprotease and the deficiency of lytic factor are minimized. In the case of antiprotease, it was found that the inhibitory effect of human serum due to elevated antiprotease content was small as compared with the resistance produced by relatively low levels of antifibrinolysin (9). Interference by antiprotease was then avoided by employing a suitable initial dilution of serum. The problem of apparent resistance arising from lytic factor deficiency, on the other hand, was avoided by the use of fibrinogen-thrombin clots containing lytic factor in adequate amount.

Secondly, by suitable control of the variables in the fibrinolytic and antifibrinolytic reaction, it was possible to employ a standard neutralization procedure which measured antifibrinolysin by the serum titer rather than by the time of dissolution of a plasma clot. It was thus possible to define the unit of measure of antibody, with a resulting greater uniformity in reporting experimental data. In addition, the antifibrinolysin content could be measured in the bloods of patients whose clots were completely resistant by the routine test. This permitted studies to be carried out on the significance of the absolute serum level as an indication of streptococcal infection (19). In this regard, it should be mentioned that the results obtained in extensive studies of the antifibrinolysin level, as determined by fibrinolysins from various strains of streptococci, have indicated that antifibrinolysins are not immunologically different, as has been asserted by some workers (12). This report will be presented in detail elsewhere.

The use of a clot formed from fibrinogen and thrombin instead of from fresh plasma has made the test adaptable to routine serological application. In general, it was found that the method of antifibrinolysin titration described was comparable in accuracy and reproducibility to other routine serological tests. Application of this test has been made in this laboratory to studies of the specificity of the antifibrinolytic response and of the frequency of such responses in streptococcal infection. The results of these studies are described in the following paper (19).

\section{SUMMARY}

By suitable control of the factors entering into the fibrinolytic reaction and its inhibition, it was possible to devise a quantitative method for the estimation of serum antifibrinolysin. The method was based on the determination of the highest serum dilution which neutralized an arbitrary unit concentration of fibrinolysin. From studies of the reproducibility of the test it was concluded that a difference of two successive dilution increments constituted a significant change in antibody content, provided the sera compared were assayed in the same run.

\section{ADDENDUM}

The method for the determination of serum antifibrinolysin has been modified so that the preliminary titration of serum could be eliminated in most instances. The method adopted at present employs 12 progressive dilutions of serum ranging from $1 / 25$ to $1 / 2100$, as given in Table II.

TABLE II

Method of serum antifibrinolysin titration

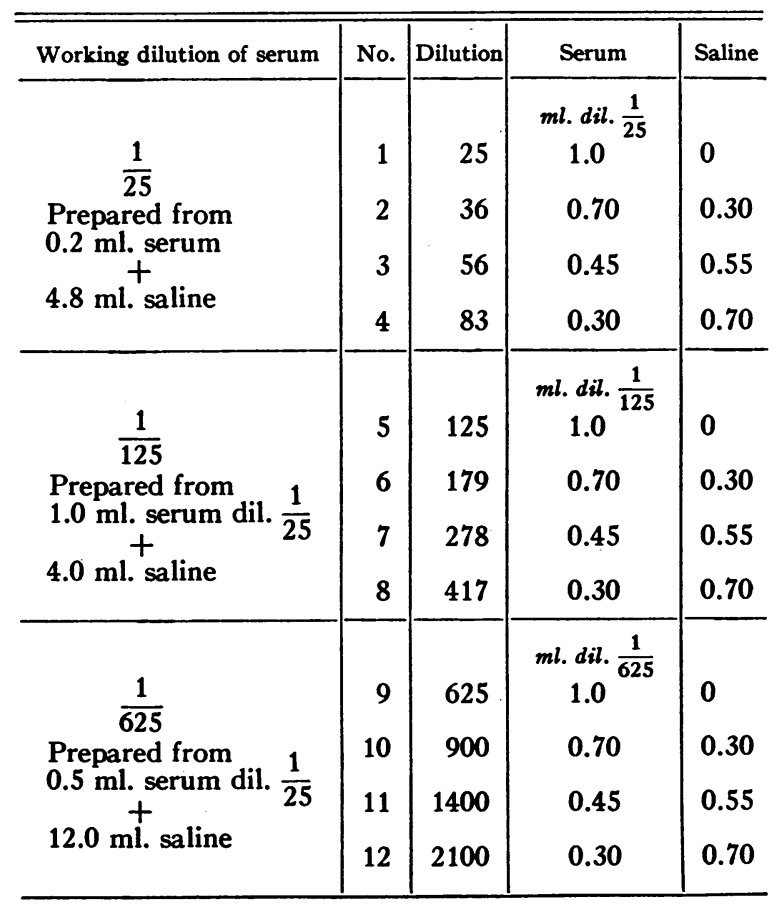


However, since very few sera exceed $1 / 417$ in titer, the test as routinely performed includes only the first 8 tubes. Titration was repeated with higher dilution increments when indicated by this 8-tube titration.

An outline of the procedure for setting up the progressive dilutions of serum is presented in Table II. It is to be pointed out that these serum dilutions are based on an exact logarithmic scale, in which each successive dilution is increased by a factor of $\mathbf{1 . 5}$.

A difference of at least two dilution increments between two sera titrated in the same run was found to represent a significant change in antifibrinolysin level.

The authors take pleasure in acknowledging the assistance of Dorothy C. Mickle, S/Sgt. Howard E. Duke, and Bettie Wooten.

\section{BIBLIOGRAPHY}

1. Tillett, W. S., and Garner, R. L., The fibrinolytic activity of hemolytic streptococci. J. Exper. Med., 1933, 58, 485.

2. Tillett, W. S., Edwards, L. B., and Garner, R. L., Fibrinolytic activity of hemolytic streptococci; the development of resistance to fibrinolysis following acute hemolytic streptococcus infections. J. Clin. Invest., 1934, 13, 47.

3. Tillett, W. S., The fibrinolytic activity of hemolytic streptococci. Bact. Rev., 1938, 2, 161.

4. Mote, J. R., and Jones, T. D., Studies of hemolytic streptococcal antibodies in control groups, rheumatic fever, and rheumatoid arthritis. J. Immunol., 1941, 41, 61.

5. Boisvert, P. L., The streptococcal antifibrinolysin test in clinical use. J. Clin. Invest., 1940, 19, 65.

6. Waaler, E., Development of antifibrinolytic properties in blood of patients with rheumatic fever, chronic infective arthritis and bacterial endocarditis. J. Clin. Invest., 1937, 16, 145.

7. Christensen, L. R., Streptococcal fibrinolysis: a pro- teolytic reaction due to a serum enzyme activated by streptococcal fibrinolysin. J. Gen. Physiol., 1945, 28, 363.

8. Commission on Acute Respiratory Diseases, and Kaplan, M. H., A quantitative study of the fibrinolysinantifibrinolysin reaction. Science, 1945, 101, 120.

9. Kaplan, M. H., Studies of streptococcal fibrinolysis. II. The inhibition of streptococcal fibrinolysis by antifibrinolysin and antiprotease. J. Clin. Invest., 1946, $25,337$.

10. Milstone, H., A factor in normal human blood which participates in streptococcal fibrinolysis. J. Immunol., 1941, 42, 109.

11. Massell, B. F., Mote, J. R., and Jones, T. D., The quantitative relation of fibrinolysin and antifibrinolysin. J. Immunol., 1939, 36, 45.

12. Mote, J. R., Massell, B. F., and Jones, T. D., Differences in hemolytic streptococcal antifibrinolysins. J. Immunol., 1939, 36, 71.

13. Cohn, E. J., Oncley, J. L., Strong, L. E., Hughes, W. L., Jr., and Armstrong, S. H., Jr., The characterization of the protein fractions of human plasma. J. Clin. Invest., 1944, 23, 417.

14. Garner, R. L., and Tillett, W. S., Biochemical studies on the fibrinolytic activity of hemolytic streptococci. J. Exper. Med., 1934, 60, 239.

15. Mote, J. R., Massell, B. F., and Jones, T. D., Factors influencing the quantitative relation of fibrinolysin and antifibrinolysin. J. Immunol., 1939, 36, 59.

16. Christensen, L. R., Quantitative determination of activity of streptococcal fibrinolysin. Proc. Soc. Exper. Biol. and Med., 1941, 46, 674.

17. Kaplan, M. H., Tagnon, H. J., Davidson, C. S., and Taylor, F. H. L., Studies on blood coagulation: the nature and properties of a proteolytic enzyme derived from plasma. J. Clin. Invest., 1942, 21, 533.

18. Hodge, B. E., and Swift, H. F., Varying hemolytic and constant combining capacity of streptolysin; influence on testing for antistreptolysins. J. Exper. Med., 1933, 58, 277.

19. Commission on Acute Respiratory Diseases, Studies of streptococcal fibrinolysis. IV. Clinical application of a quantitative antifibrinolysin test. J. Clin. Invest., 1946, 25, 352. 